\title{
Algunas reflexiones sobre la solución de diferencias en la Organización Mundial del Comercio
}

\author{
Some comments on the settlement of \\ disputes within the WTO.
}

\author{
Álvaro Espinoza Soto*
}

\section{Resumen}

El sistema de solución de diferencias de la Organización Mundial del Comercio (OMC) presenta diversos asuntos de interés para su estudio. Este trabajo pretende abordar solo algunos de ellos, en el contexto del derecho internacional público. En concreto: la naturaleza del conflicto, si hay ejercicio de una función judicial y si es pertinente calificarlo como un tribunal; y si un precedente es jurídicamente vinculante para casos futuros.

Palabras clave: diferencia, jurisprudencia, precedente, Grupo Especial, Órgano de Apelación.

\section{Abstract}

Many aspects of the Dispute Settlement System of the World Trade Organization (WTO) are worth studying. This article aims to analyze just some of those topics, in the context of Public International Law: the nature of the dispute; whether there is an exercise of a judicial function and whether it is appropriate to characterize it as a tribunal or court; and, whether a precedent is legally binding for future cases.

KeYWords: dispute, jurisprudence, precedent, Panel, Appellate Body

Asesor jurídico en la Dirección General de Relaciones Económicas Internacionales, Ministerio de Relaciones Exteriores de Chile.<aespinoza@direcon.cl>. 

Álvaro Espinoza • Algunas reflexiones sobre la solución en la organización mundial...

\section{I. ¿Controversia O DIFERENCIA?}

Es variada la terminología empleada para designar la contraposición de interpretaciones sobre una cuestión cuya esencia es jurídica. Esta falta de entendimiento importa discutir si existe o no una obligación de fuente internacional, o bien, si aquella obligación existe, precisar si procede cumplirla con determinada calificación, forma u oportunidad. Así, pueden encontrarse los vocablos 'conflicto', 'contienda', 'controversia', 'diferendo' o 'disputa', que se usan indistintamente con este fin.

Si se comparan las versiones oficiales en español y en inglés de la Carta de las Naciones Unidas se advierte el término 'controversia' como equivalente de la voz inglesa dispute ${ }^{1}$, cuestión que se repite en el texto de diversos acuerdos comerciales contemporáneos ${ }^{2}$. En la $\mathrm{OMC}$, el mecanismo comprometido con el propósito de arreglar los posibles conflictos entre sus Miembros consta en el Entendimiento de Solución de

1 Carta de la Naciones Unidas, Artículo 2 párrafo 3: «Los Miembros de la Organización arreglarán sus controversias internacionales por medios pacíficos...».

2 Como ejemplos de equivalencia entre dispute y 'controversia' (al igual que en las naciones unidas cabe citar, entre otros, el Capítulo 20 del Tratado de Libre Comercio de América del Norte, (NAFTA en inglés); el Capítulo 22 del Tratado de Libre Comercio entre Chile y Estados Unidos; o el Título VIII de la Parte IV del Acuerdo de Asociación entre Chile y la Unión Europea.
Diferencias $(\mathrm{ESD})^{3}$, y aquí destaca la palabra «diferencia», y no controversia, como sinónimo oficial frente a la versión inglesa dispute ${ }^{4}$.

¿Qué pudo motivar esta variación en el lenguaje? ¿Pudiera haber sido algún desacierto en la traducción, luego confirmado por el acuerdo político de las Partes al suscribir el acuerdo internacional? Argumentar que se debería a la traducción no parece muy sostenible si se considera el detallado trabajo de las comisiones de revisión, las que afinan los textos oficiales para la firma definitiva y, especialmente, si 'diferencia' es una palabra que figura en un título de un Anexo muy vistoso en los Acuerdos de la OMC, el ESD ${ }^{5}$, por tratarse de un mecanismo de particular interés durante las negociaciones de la Ronda Uruguay ${ }^{6}$.

$\mathrm{El}$ antecedente histórico inmediato de la OMC, el $\mathrm{GATT}^{7}$ no mencionó en

3 Nombre abreviado con que se conoce el «Entendimiento relativo a las normas y procedimientos por los que se rige la solución de diferencias» (Anexo 2 del Acuerdo de Marrakech por el que se establece la $\mathrm{OMC}$ ).

4 En inglés es DSU: Dispute Settlement Understanding.

5 El Anexo 2 del Acuerdo de la OMC.

6 No presta mucha utilidad, para los efectos de este análisis, recurrir al francés como tercer idioma oficial de la OMC, pues la palabra différend aparece en los principios de la Carta de las Naciones Unidas. Además, différend significa 'diferencia' y también litigio o controversia.

7 GATT: sigla inglesa para designar el General Agreement on Tariffs and Trade, Acuerdo General sobre Aranceles Aduaneros y Comercio, tratado internacional 
sus disposiciones las palabras 'controversia', 'diferencia' ni «disputa»; solo contempló el mecanismo de consultas entre sus Partes Contratantes, cuyo artículo clave es el XXIII, para ser invocado por la Parte que alegue sufrir «anulación»o «menoscabo» de las ventajas obtenidas. Pero si las Partes no logran arreglar «la cuestión», esta podrá someterse a las demás Partes Contratantes del GATT para que formulen recomendaciones o dicten una resolución. El Artículo XXIII no reguló cómo las Partes Contratantes debían proceder para resolver lo sometido a su decisión y, sobre la base de dicha norma, se generó una práctica que con los años se codificó en diversos acuerdos suscritos por las Partes Contratantes del GATT. Esta codificación consolidó la experiencia acumulada como un aporte a las negociaciones, de las que resultó el actual ESD. En esos acuerdos ${ }^{8}$ aparece el término dispute ya traducido como 'diferencia'.

Aunque las palabras 'diferencia' y 'controversia' se entiendan como sinó-

suscrito mediante un Protocolo de Aplicación Provisional el 30 de octubre de 1947 y que entró en vigencia el 1 de enero de 1948.

8 Entendimiento de 28 de noviembre de 1979 relativo a las notificaciones, las consultas, la solución de diferencias y la vigilancia; Declaración Ministerial de 29 de noviembre de 1982, Decisión sobre solución de diferencias; Decisión de 30 de noviembre de 1984 sobre solución de diferencias; Decisión de 12 de abril de 1989 sobre las mejoras de las normas y procedimientos de solución de diferencias del GATT. nimos, puede percibirse en esta última un matiz que sugiere una confrontación irreconciliable entre las partes y esa falta de entendimiento es la que justifica recurrir a la decisión de un tercero imparcial dotado de jurisdicción, sea un órgano arbitral o judicial.

Ahora bien, ciertas reglas del ESD apuntan a que la presencia de la palabra 'diferencia' no fue casual. En primer lugar, el artículo 3 párrafo 10: "Queda entendido que las solicitudes de conciliación y el recurso al procedimiento de solución de diferencias no deberán estar concebidos ni ser considerados como actos contenciosos y que, si surge una diferencia, todos los Miembros entablarán este procedimiento de buena fe y esforzándose por resolverla». Este párrafo 10 recoge el fundamental principio general de derecho que consiste en obrar de buena fe y agrega una curiosa calificación: no considera el recurso a la solución de diferencias como un acto contencioso, lo que es curioso pues parece haber intentado establecer que recurrir al mecanismo no conlleva ánimo de enemistad ni de agresión, ya que activarlo confirma la buena fe en desear arreglar un desacuerdo. De todos modos, la disposición resulta sorprendente, pues los actos para abordar una controversia bien pueden calificarse como "actos contenciosos» en los que cada parte interesada, de modo pacífico, hará valer sus derechos, reclamos y argumentaciones. En refuerzo de lo anterior, tras la amarga experiencia de las guerras mundiales, la comunidad internacional concordó en 
Álvaro Espinoza • Algunas reflexiones sobre la solución en la organización mundial...

que las controversias deben resolverse por medios pacíficos ${ }^{9} \mathrm{e}$ incluso algunos tratadistas sostienen que ello constituye un principio de derecho internacional con carácter de ius cogens (Pastror Ridruejo, 2003, 45).

Aquella expresa valoración del ESD sobre lo "no contencioso", debe analizarse en el contexto de sus demás reglas, de las que quizá puede extraerse que los redactores del ESD desearon marcar una diferencia con otras instituciones de jurisdicción internacional ${ }^{10}$, puesto que permite a las partes mantener su poder político para negociar directamente una solución, incluso mientas pende la instancia jurisdiccional del grupo especial ${ }^{11}$. Por ello una diferencia puede ser tratada en el ESD a través de medios de solución políticos junto con los medios jurisdiccionales.

El primer paso del mecanismo es la etapa de 'consultas', que es el diálogo directo entre las partes, instancia en la que «deberán tratar de llegar a una solución satisfactoria de la cuestión antes de recurrir a otras medidas» del ESD ${ }^{12}$. Si las consultas no permiten resolver la diferencia en un plazo de 60 días contados desde que se solicitaron ${ }^{13}$, el

9 Como se recoge claramente en los Principios de la Carta de las Naciones Unidas (artículo 2 párrafo 3) y luego en el Capítulo VI de la misma Carta.

10 En este sentido en el ESD no figuran palabras como «tribunal», "corte», "sentencia» o «fallo».

11 El grupo especial es más conocido por su término en inglés: panel.

12 ESD, artículo 4 párrafo 5.

13 Hay quienes piensan que si en la OMC un reclamante tiene la libertad para pedir directa y unilateralmente el establecimiento de un grupo especial ${ }^{14}$.

Si la parte reclamante así lo pide se establecerá un grupo especial a más tardar en la reunión siguiente a aquella en que la petición haya figurado por primera vez como punto en el orden del día ${ }^{15}$. Dicho de modo más simple: la parte reclamante establecerá el grupo especial de forma automática en la reunión siguiente, si en la reunión previa la parte requerida se opuso a ello ${ }^{16}$. ¿Por qué el ESD permite una postergación generada por la voluntad de la parte requerida? La racionalidad que se aprecia con tal dilación es otorgar

caso se plantea formalmente como diferencia, la etapa de consultas, por lo breve, vendría a constituir para el reclamante solamente un trámite inicial de procedimiento para ser prontamente agotado, con el verdadero propósito de establecer la vía jurisdiccional del grupo especial. Pero ese pensamiento no considera que las consultas, llevadas efectivamente de buena fe, podrían generar un acuerdo que solucione la diferencia; además, que iniciada la etapa de consultas es evidente para la parte requerida que de no lograr un pronto acuerdo será inminente el establecimiento de un grupo especial, lo que puede constituir un aliciente para lograr un acuerdo.

14 ESD, artículo 4 párrafo 7.

15 Como "punto en el orden del día» el artículo 6.1 del ESD se refiere a que la petición para establecer un grupo especial se haya incluido como "tema a tratar en la agenda» y se haya discutido en esa reunión previa.

16 La norma no impide que la parte requerida consienta en que el grupo especial se establezca en la primera sesión en que se solicita. 
la última oportunidad a las partes para que negocien un arreglo de la diferencia antes de que se establezca el grupo especial, cuestión que además no es del todo absoluta, pues ninguna norma del ESD exige que la etapa de consultas caduque tras la petición o el establecimiento de un grupo especial. En efecto, el ESD no espera que las partes estén de acuerdo en dar por terminadas las consultas, ni tampoco prevé un 'abandono de la instancia' de las mismas si la parte reclamante no ejecuta otra acción y deja pasar el tiempo sin más. Aunque pudiera pensarse que la intervención del grupo especial haría operar, tácitamente, la preclusión de las consultas, el ESD concede al reclamante la facultad de solicitar que el grupo especial suspenda sus trabajos por un plazo no superior a 12 meses $^{17}$ y la justificación para esta válvula de escape es la inminente posibilidad de arribar a un arreglo en la diferencia. Esa norma no lo dice expresamente, pero confirma que la etapa de consultas no se había agotado.

Pero aún queda otra figura especial, que es la etapa intermedia de reexa$\operatorname{men}^{18}$, consistente en que el grupo especial pondrá en conocimiento de las partes los capítulos expositivos de su proyecto de informe $\mathrm{y}$, tras recibir las observaciones que las partes deseen manifestar, les dará nuevamente traslado del ahora informe provisional, que incluirá los capítulos expositivos y las constataciones y conclusiones, para recibir de ellas nuevas observaciones

17 ESD artículo 12 párrafo 12.

18 ESD artículo 15. $y$, si lo desean, solicitar que se reexaminen aspectos concretos del informe provisional ${ }^{19}$. Hay quienes ven en esta etapa una consideración innecesaria en favor de las partes, que implica retardar la distribución del informe definitivo para el escrutinio multilateral. Sin embargo, aunque esta regla tampoco lo diga expresamente, el hecho de que el propio grupo especial dé a conocer a las partes las conclusiones finales de un informe que aún no suscribe constituye una oportunidad única para alentarlas a negociar una solución mutuamente convenida y así evitar que el informe definitivo salga a la luz pública.

Ninguna de las figuras particulares que alienta al mutuo acuerdo está prevista en la etapa posterior de apelación, el ESD nada dice al respecto ${ }^{20}$. No obstante, el propio Órgano de Apelación dictó $^{21}$ sus propios procedimientos de trabajo ${ }^{22}$, que contempla dos situaciones basadas en las reglas generales del derecho procesal. Por una parte, el desistimiento del apelante y, por la

19 Esta posibilidad de exhibir con antelación el informe es una situación que no se prevé en otras entidades internacionales, como la Corte Internacional de Justicia.

20 Tal vez ello se deba al muy breve plazo previsto para evacuar el informe de apelación: entre 60 y 90 días contados desde que el apelante notifique por escrito su intención de apelar.

21 Así lo autoriza el artículo 17 párrafo 9 del ESD.

22 Los procedimientos de trabajo para el examen en apelación constan en la última edición actualizada en el documento $\mathrm{WT} / \mathrm{AB} / \mathrm{WP} / 5$, de la OMC de 4 de enero de 2005. 
Álvaro Espinoza • Algunas reflexiones sobre la solución en la organización mundial...

otra, que las partes hayan notificado a la OMC una solución mutuamente acordada ${ }^{23}$.

En suma, la palabra 'diferencia' que emplea el ESD, en su versión oficial en idioma español, denota que el sistema trata las tensiones comerciales de los miembros evitando caracterizar la confrontación en el sentido clásico de la controversia, pues, además de la brevedad de los plazos que prevé su procedimiento $^{24}$, éste fue concebido de modo de privilegiar el pronto arreglo entre las partes, compatible con los compromisos comerciales multilaterales, y así dar por solucionada la diferencia antes que concluir el proceso de un grupo especial. Como lo indica el ESD: «El objetivo del mecanismo de solución de diferencias es hallar una solución positiva a las diferencias. Se debe dar siempre preferencia a una solución mutuamente aceptable para las partes en la diferencia y que esté en conformidad con los acuerdos abarcados» ${ }^{25}$.

23 Regla 30 de los procedimientos de trabajo del Órgano de Apelación.

24 En comparación con los procedimientos de otras instancias de jurisdicción internacional.

25 ESD artículo 3 párrafo 7.

\section{II. ¿EL SISTEMA ES UN TRIBUNAL} INTERNACIONAL?

En la era del GATT el artículo XXIII constituyó el sustento para gatillar el recurso a la resolución de conflictos entre partes, pero al someter el asunto a las demás Partes Contratantes, no reguló cómo ellas procurarían arribar a una decisión. Al comienzo esa situación generó una práctica en que las disputas se trataban en una reunión plenaria semestral, luego en un Comité de Mediación y después en grupos de trabajo que examinaban todas las disputas o se centraban en algunas específicas, para así formular sus recomendaciones. Pero esos grupos de trabajo se formaban con miembros de las delegaciones de las mismas Partes Contratantes, las que, naturalmente, recibían instrucciones de sus propios gobiernos. Un cambio importante ocurrió en 1955 al establecerse grupos de expertos ad hoc, que asumieron su tarea en su personal capacidad, sin representar a ningún gobierno, y formulaban directamente sus conclusiones al Consejo del GATT. Posteriormente, ese grupo de expertos pasó a denominarse 'grupo especial' 26 y las conclusiones de sus informes se desarrollaron para elaborar una decisión fundada en las reglas del GATT y sus disciplinas, con una orientación más arbitral o judicial que un medio

26 El nombre «grupo especial» se mantuvo en el ESD. En idioma inglés se le denomina panel, voz bastante usada en Chile, pero en este trabajo se prefiere emplear el nombre oficial en español. 
de conciliación o negociación política. A comienzos del decenio de 1980, el trabajo de los grupos especiales se volvió más riguroso en razonar y fundar sus decisiones sobre bases jurídicas, porque la Secretaría del GATT dispuso de mayor asistencia de juristas ${ }^{27}$.

En los años siguientes las Partes Contratantes codificaron las prácticas seguidas en diversas decisiones, entre ellas la Decisión de 12 de abril de 1989 sobre mejoras de normas y procedimientos de solución de diferencias ${ }^{28}$ que fue determinante para el futuro del sistema, pues fijó plazos precisos ${ }^{29}$, acordó la posibilidad de solicitar directamente la intervención de un grupo especial y que este se estableciera si se solicitaba por segunda vez. Esa Decisión sentó las bases del futuro ESD de la OMC al instaurar la automaticidad del procedimiento $^{30}$, de modo que sus resultados no se vieran frustrados por la falta de consenso entre las propias Partes Contratantes del Acuerdo.

Lo que generó un mayor interés de los grupos económicos.

28 Se adoptó sobre la base de los acuerdos de la Reunión Ministerial de 1988 que tuvo lugar en Montreal, Canadá.

29 Que debe responderse a la solicitud de consultas dentro de los 10 días de recibida, que las consultas se celebrarán en los 30 días desde que se solicitó y que a los 60 días de consultas, el reclamante puede pedir que se establezca un grupo especial.

30 Antes de esta Decisión, las Partes cuyos intereses se afectaban con el procedimiento podían impedir el consenso, con su negativa.
Una particularidad novedosa del ESD, resultado de lo negociado en la Ronda Uruguay, fue la incorporación en la naciente OMC de un órgano permanente para resolver las apelaciones planteadas contra las decisiones de un grupo especial. Su inclusión obedeció a que ya en 1989 el procedimiento mediante grupos especiales era automático, por lo que ahora el ESD enfatizó el avance gradual de sus etapas hasta la adopción del informe, que ya no pueda bloquearse. Cabía preguntarse qué ocurriría si ese informe no contenía un razonamiento de calidad que perjudicase los intereses de las partes y la credibilidad del mismo sistema. Claramente el informe debía aprobarse, pese a su contenido. Por ello fue preciso agregar la instancia de revisión en apelación de los informes de grupos especiales, y con lo cual sólo se pretendió asegurar el mecanismo de la adopción automática. Ese fue «el humilde origen del Órgano de Apelación» (Van den Bossche, 2005; 64 y 65 ).

Como lo ha dejado claro la historia del GATT y ahora lo confirman las disposiciones vigentes del ESD, los grupos especiales y el Órgano de Apelación se concibieron para actuar con independencia de los intereses particulares de los Miembros de la OMC. Asimismo, el ESD dispuso los informes de los grupos especiales y del Órgano de Apelación deben ser obligatoriamente aprobados por los Miembros de la $\mathrm{OMC}^{31}$, por lo

31 ESD artículos 16 y 17. 
Álvaro Espinoza • Algunas reflexiones sobre la solución en la organización mundial...

que constituye «un elemento de jurisdicción» (Abi-Saab, 2005; 9).

Por otra parte, una vez que un grupo especial se establece, los Miembros de la OMC, constituidos a través del Órgano de Solución de Diferencias (OSD), deben aprobar el mandato para las actuaciones del grupo especial ${ }^{32}$, cuyas cláusulas, generalmente tienen un formato estandarizado ${ }^{33}$, sin perjuicio de que las partes en la diferencia puedan acordar otra cosa. En caso, de que el mandato no sea uniforme, se percibe un elemento que pareciera ser propio de un arbitraje (Abi-Saab, 2005; 9 y 10). En este mismo sentido (cierta similitud al arbitraje), las partes pueden elegir a los miembros del grupo especial ya establecido para conocer de la diferencia ${ }^{34}$.

De acuerdo con su mandato, el grupo especial debe examinar las reclamaciones de las partes y, sobre la base de las normas de los Acuerdos de la OMC alegados en la diferencia, formular sus recomendaciones en un informe. Por su parte, al Órgano de Apelación le compete conocer de la apelación, la que

\section{ESD artículo 7.}

33 «Examinar, a la luz de las disposiciones pertinentes (de los acuerdos abarcados que hayan invocado las partes en la diferencia), el asunto sometido al OSD por (nombre de la parte) en el documento... y formular conclusiones que ayuden al OSD a hacer las recomendaciones o dictar las resoluciones previstas en dicho acuerdo.» (artículo 7 párrafo 1 del ESD)

34 De conformidad con los criterios que figuran en el artículo 8 del ESD. «tendrá únicamente por objeto las cuestiones de derecho tratadas en el informe del grupo especial y las interpretaciones jurídicas formuladas por éste» ${ }^{35} \mathrm{y}$ "podrá confirmar, modificar o revocar las constataciones y conclusiones jurídicas del grupo especial» ${ }^{36}$.

Si un grupo especial o el Órgano de Apelación llegan a la conclusión de "que una medida es incompatible con un acuerdo adoptado, recomendarán que el Miembro afectado la ajuste a ese acuerdo"; además, el grupo especial o el Órgano de Apelación "podrán sugerir la forma en que el Miembro afectado podría aplicarlas.» ${ }^{37}$ Entonces, el ejercicio jurisdiccional consiste en determinar si, para un caso alegado como violación de una obligación, la medida impugnada contraviene los compromisos de ese Miembro frente a los Acuerdos de la OMC. Una vez que se ha establecido que hay violación, de ese acuerdo los órganos (grupo especial y de Apelación) sólo les cabe, en la conclusión de sus informes, "recomendar que el OSD pida al Miembro afectado que ponga la medida cuestionada en conformidad con el Acuerdo de que se trata». Esto merece destacarse pues ni el grupo especial ni el Órgano de Apelación están facultados para indicar al Miembro cómo este debe cumplir con sus obligaciones internacionales. No debe perderse de vista que los Miembros de la OMC, pese a los

\footnotetext{
5 ESD artículo 17 párrafo 6.

$36 \quad$ ESD artículo 17 párrafo 13.

37 ESD artículo 19 párrafo 1.
} 
compromisos convencionales que han asumido, mantienen su calidad de sujetos de derecho internacional con plena capacidad y soberanía para determinar sus propias medidas internas y prever los efectos que ellas causen en el plano internacional. En otras palabras, el Miembro tiene el poder para adoptar medidas en la forma, sentido y alcance que esti me convenientes, con la sola limitación de no contravenir sus compromisos internacionales.

Corresponde examinar otra disposición general del ESD que es pertinente en este contexto: «De no llegarse a una solución de mutuo acuerdo, el primer objetivo del mecanismo de solución de diferencias será en general conseguir la supresión de las medidas de que se trate si se constata que éstas son incompatibles con las disposiciones de cualquiera de los acuerdos abarcados» ${ }^{38}$. ¿El ESD se propuso que el Miembro deba derogar la medida cuestionada? Claramente no. El sistema persigue que se eliminen los elementos y efectos de la medida discutida que resultan incompatibles con las obligaciones de los Acuerdos de la OMC. Entonces, cobra mayor sentido que los grupos especiales y el Órgano de Apelación solo puedan plantear sugerencias respecto del cumplimiento ${ }^{39}$.

ESD artículo 3 párrafo 7.

39 Precisamente por el elemento de soberanía, tanto los grupos especiales como el Órgano de Apelación han sido muy cautelosos en formular sugerencias y respecto del caso en que una parte interesada así lo hubiere solicitado.
Se advertirá otra sutileza en las conclusiones de los informes del grupo especial o de apelación (una vez establecido que la medida viola un Acuerdo) cuando recomiendan que «el OSD pida al Miembro afectado que ponga la medida cuestionada en conformidad con el Acuerdo». Es decir, no plantean directamente su recomendación al Miembro, sino que la formulan al OSD para que este último sea el que lo pida al Miembro afectado. Pero esa cláusula usual en las conclusiones de los informes no es verdaderamente una sutileza, sino que obedece a un fundamento mayor.

En esta materia queda la sensación de que toda decisión en materia de solución de diferencias sería de responsabilidad de los grupos especiales y de apelación (si hay apelación, claro está). No cabe duda que la jurisdicción, entendida para estos efectos como el conocimiento de las alegaciones de las partes y su posterior decisión motivada, es de competencia de los grupos especiales y del Órgano de Apelación. Sin embargo, los informes en cuanto tales no adquieren fuerza vinculante sino una vez que son adoptados por el OSD y a este último le corresponde la posterior supervisión del cumplimiento de los informes adoptados.

Podrá argumentarse desde otra perspectiva que la esencia del sistema es el ejercicio de la función de adjudicación, que es efectuada por los grupos especiales y el Órgano de Apelación, al determinar si una medida cuestionada es incompatible o no frente a los compromisos internacionales, puesto que 
Álvaro Espinoza • Algunas reflexiones sobre la solución en la organización mundial...

el OSD, gracias a la automaticidad del sistema, debe en todo caso adoptar los informes referidos. Entonces, con este razonamiento la verdadera autoridad radicaría en los órganos de adjudicación.

Parece algo extremo sostener, desde la óptica puramente jurídica, que los grupos especiales ejerzan funciones judiciales y que el Órgano de Apelación sea un Tribunal del Comercio Mundial. Aunque algunos autores derechamente le atribuyan mérito para considerarlo como tal (Van den Bossche, 2005; 64). Es comprensible y se puede estar de acuerdo en que, dada la alta función encomendada por el ESD al Órgano de Apelación, se perciba su autoridad y los alcances de sus pronunciamientos como los de un verdadero tribunal. En ese sentido, un claro argumento para favorecer tal idea se encuentra en que el ESD estableció un órgano "permanente» de apelación ${ }^{40}$, a diferencia de los grupos especiales que deben establecerse e integrarse para cada caso en concreto.

Pero al mismo tiempo llama la atención que los negociadores del ESD tuvieron especial cuidado en no llamarle 'Corte' ni 'tribunal', y no emplearon la palabra «judicial» para referirse a las funciones del Órgano o de los grupos especiales, además de llamar informe al resultado de sus trabajos, evitando así los términos 'fallo' o 'sentencia', y, por último, que refirieron a quienes integran el Órgano y los grupos especiales simplemente como «personas».

$40 \quad$ ESD artículo 17 párrafo 1.
Pauwelyn cita un pasaje de un informe del Órgano de Apelación, pronunciado en la diferencia sobre implementación en el caso 'MéxicoInvestigación antidumping sobre el jarabe de maíz con alta concentración de fructosa procedente de Estados Unidos', en cuyo párrafo 36 se señala: "...para respetar las debidas garantías procesales y para ejercer debidamente la función judicial, los grupos especiales tienen que abordar las cuestiones que le sometan las partes en una diferencia» (Pauwelyn, 2003; 442). ${ }^{41}$ Pero está claro que la calificación de la función judicial fue atribuida por el propio Órgano y no por los textos jurídicos. Entonces, la clave para entender este carácter judicial es, por una parte, la tarea de determinar si una medida de un Miembro es compatible o no frente a la OMC (representada por el Órgano de Apelación y los grupos especiales) y, por la otra, la subsecuente adopción automática de parte del OSD y su tarea de supervisión de la forma en que el Miembro afectado cumplirá la medida cuestionada.

Para Pauwelyn lo determinante es la independencia con que actúan los grupos especiales y el Órgano de Apelación al redactar sus razonamientos conforme a derecho el hecho de que sus pronunciamientos en los informes

${ }^{41}$ Así lo piensan también PALMETER y MAVROIDIS, que los informes son «decisiones judiciales de la OMC». Hay otros que piensan que la función sería cuasijudicial. 
son automáticamente adoptados por el OSD. Entonces concluye que ellos son «tribunales judiciales en el sentido del derecho internacional» (Pauwelyn, 2003; 442). La última cita de este autor ayuda a ponderar los juicios en esta materia. La sociedad internacional aún está lejos de contar con poderes regulador y juzgador centralizados.

Pero más allá de calificar como judiciales las funciones de los grupos especiales y del Órgano de Apelación, cabe precisar que el sistema de solución de diferencias de la OMC es en parte ejercido por ellos porque sus competencias se complementan con el poder de imperio que el ESD radica en los propios Miembros de la OMC (reunidos como OSD), mediante la adopción con que sancionan obligatoriamente los informes de grupos especiales y de apelación ${ }^{42}$. El debido cumplimiento se asegura, en gran parte, con la automaticidad de las aprobaciones ${ }^{43}$, lo que

42 Una de las funciones de la OMC es administrar el ESD. El Consejo General de la OMC se reúne a desempeñar las funciones del OSD. El ESD estableció el OSD para administrar las normas y procedimientos en solución de diferencias, por lo que «el OSD estará facultado para establecer grupos especiales, adoptar los informes de los grupos especiales y del Órgano de Apelación, vigilar la aplicación de las resoluciones y recomendaciones y autorizar la suspensión de concesiones y otras obligaciones en el marco de los acuerdos abarcados.»

43 En rigor, una aprobación no es automática en términos absolutos, puesto que, al menos teóricamente es posible que se dé la situación en que un miembro que obtuvo un informe favorable esté de acuerdo es clave para mantener un sistema que goce de credibilidad.

Más allá de los informes de apelación y de los grupos especiales, Jackson afirma que el «Sistema de Solución de Diferencias [de la OMC] ha sido descrito como el más importante y poderoso que cualquier otro tribunal internacional, aunque algunos reserven esa posición de privilegio a la Corte Internacional de Justicia» (Jackson, 2006; 135).

Como se aprecia, una cosa es que los textos jurídicos de la OMC no le hayan reconocido expresamente funciones de naturaleza judicial a las tareas de los grupos especiales y al Órgano de Apelación. Sin embargo, no cabe duda que estas funciones sí son actuaciones de adjudicación, lo que implica necesariamente ejercer parte de la función jurisdiccional, y esta última se completa con la manifestación del imperio (adopción forzosa y vinculante, además del control posterior del estado de cumplimiento) que es cumplida por los propios Miembros de la OMC, constituidos como OSD. En conclusión, se trata de un sistema autocontenido en el que las normas del tratado internacional permiten a la OMC, como institución, dictar sus propias resoluciones, las que (a diferencia de otras resoluciones con mero efecto declarativo) constituyen

en no adoptarlo en conjunto con la voluntad de los demás Miembros de la OMC. 
Álvaro Espinoza • Algunas reflexiones sobre la solución en la organización mundial...

fuente de derecho internacional ${ }^{44}$ respecto de disputas específicas.

\section{LA FUERZA DE LOS PRECEDENTES}

Los textos tradicionales de derecho internacional público explican la jurisprudencia, como fuente formal, a partir de la estructura del Estatuto de la Corte Internacional de Justicia (CIJ), cuyo artículo $38 \mathrm{~N}^{\circ} 1$ indica, en la parte que interesa: "La Corte, cuya función es decidir conforme al derecho internacional las controversias que le sean sometidas, deberá aplicar: [...] d. las decisiones judiciales [...] como medio auxiliar para la determinación de las reglas de derecho, sin perjuicio de lo dispuesto en el artículo 59.» A su turno, el artículo 59 del Estatuto dispone: «La decisión de la Corte no es obligatoria sino para las partes en litigio y respecto del caso que ha sido decidido".

Dos son los criterios distintivos de la jurisprudencia que consigna ese Estatuto para las decisiones de la CIJ: que un dictamen judicial obliga solo a las partes del caso en que se ha pronunciado y que, en consonancia con ello, una sentencia será un elemento auxiliar en la determinación de las fuentes de

$44 \quad$ Algunos autores de derecho internacional llaman a esta fuente de derecho: «resoluciones de los organismos internacionales» o «legislación internacional» (fuente no prevista en las menciones del artículo 38 del Estatuto de la Corte Internacional de Justicia). derecho aplicables a un caso diverso. Es decir, la jurisprudencia, en cuanto fallo es una fuente formal de derecho respecto del caso en que se dicta, pues más allá de aplicar las disposiciones de un tratado vigente entre las mismas partes, su dictamen está creando una solución del caso, aunque aplique normas convencionales, a través del mismo fallo que constituye la norma o fuente directa de decisión de ese caso..$^{45}$ Entonces, lo «auxiliar» cobra sentido respecto del fallo que se pueda tomar en cuenta para la resolución de un caso distinto. Visto desde otra perspectiva, la sentencia de un caso previo carece de imperativo regulatorio en el caso por resolver, pero alguna fuerza puede tener. $\mathrm{Al}$ igual que la costumbre internacional, los dictámenes de órganos judiciales internacionales extraen sus conclusiones de los principios generales propios de la comunidad internacional, y tales principios se recogen en los fallos internacionales, como una suerte de 'costumbre judicial' (Véase Pastor Ridruejo, 2003; $82,83)$. Por ello bien podría afirmarse

45 Hay autores que piensan que las decisiones jurisdiccionales no crean un derecho particular para las partes en conflicto, sino que solo se limitan a aplicar el derecho convencional ya existente. Un ejemplo a citar es Palmeter \& Mavroidis, quienes, refiriéndose a la $\mathrm{OMC}$, indican que las «decisiones aplican el derecho y no lo crean, pues en rigor esas decisiones no son fuentes de derecho en el mismo sentido que las disposiciones del tratado» (lo curioso es que ambos autores igualmente sostienen que los informes de grupos especiales y de apelación «son las decisiones judiciales de la OMC»). 
que las sentencias judiciales de otros casos pudieran estimarse como fuente material del derecho internacional, es decir, un importante elemento de inspiración para la creación de otras normas contenidas en fallos posteriores.

Ni el GATT ni los Acuerdos de la OMC contemplaron normas similares a las de los artículos 38 y 59 del Estatuto de la CIJ. Ello puede explicarse, como ya se indicó para el caso de la OMC, por el cuidado de los negociadores en no atribuir términos explícitos de naturaleza judicial a las instituciones del sistema de solución de diferencias del ESD. No obstante, los grupos especiales y el Órgano de Apelación son instancias de adjudicación, con un mandato preciso, que en el hecho funcionan como un verdadero tribunal y sin perjuicio de que algunos autores le atribuyan el carácter de tribunal (especialmente al Órgano de Apelación). Pero del pronunciamiento de estas jurisdicciones $¿$ deben entenderse sus conclusiones aplicables solo respecto de aquel caso que las motiva o bien sus decisiones podrían tener efectos sobre otros casos?

Una cosa es considerar útil el contenido de un fallo previo y emplear sus criterios en el caso actual, en el sentido en que Couture define la jurisprudencia, como: "conjunto de decisiones de los tribunales sobre una materia determinada, emitidas con ocasión de los juicios sometidos a su resolución, los cuales aún no teniendo fuerza obligatoria, se imponen por el valor persuasivo de sus razones y la autoridad del órgano del que emanen» (Couture, 1983; 372).
Pero una situación distinta de la anterior es estimar que ese fallo deba ser tomado en cuenta forzosamente. Como ocurre en el sistema del common law con el principio stare decisis ${ }^{46}$, por el que «un tribunal debiera seguir sus propias decisiones y aquellas de otros tribunales de igual o superior jerarquía» (Brownlie, 2003; xlii).

Para Jackson el 'efecto precedente' puede entenderse por la práctica desarrollada en la historia del GATT, que se basó en escasas disposiciones de ese tra$\operatorname{tado}^{47}$, considerando, además, la evolución experimentada por los informes de los grupos especiales hacia un enfoque legalista en sus decisiones. Pero si los grupos especiales citaban otros casos en apoyo de su propia interpretación, ello no equivalía al principio stare decisis sino solo a un 'efecto precedente', algo menos riguroso que una jurisprudencia vinculante (Jackson, 2006; 176).

Nunca hubo una posición de consenso respecto del estatus y los efectos de los informes pronunciados en la época del GATT y adoptados ${ }^{48}$ por las Partes Contratantes. Jackson enuncia las diversas tesis que hubo al respecto: 1) el informe adoptado es una mera recomendación que, si no se sigue, podría activar la aplicación de contramedidas (retorsiones); 2) el informe adoptado genera la obligación de cumplirlo y además envuelve una noción de precedente

46 Que significa «estarse a lo decidido».

47 A diferencia de hoy con los voluminosos Acuerdos de la OMC.

48 Los informes no aprobados nunca produjeron efectos jurídicos. 
Álvaro Espinoza • Algunas reflexiones sobre la solución en la organización mundial...

(afectando a aquellas Partes Contratantes del GATT que no intervinieron en el caso); 3) el informe solo obliga a las partes en la diferencia, y no tiene el efecto de precedente; 4) la adopción del informe por las Partes Contratantes equivaldría a una resolución definitiva de las mismas para interpretar las disposiciones del GATT; y 5) la adopción sería «una práctica ulteriormente seguida en la aplicación del tratado por la cual conste el acuerdo de las partes acerca de la interpretación del tratado", en los términos recogidos en la Convención de Viena sobre el Derecho de los Tratados $^{49}$ (Jackson, 2000; 125-129).

Pero la entrada en vigencia de los Acuerdos de la OMC motivó una nueva reflexión frente al estatus de los informes adoptados en la era del GATT. En efecto, las cuatro siguientes disposiciones del sistema OMC indican:

1) "Salvo disposición en contrario [...], la OMC se regirá por las decisiones, procedimientos y práctica consuetudinaria de las PARTES CONTRATANTES del GATT de 1947 y los órganos establecidos en el marco del mismo» ${ }^{50}$.

2) «El Acuerdo General sobre Aranceles Aduaneros y Comercio de 1994 ( «GATT de 1994») comprenderá: [...] las demás decisiones de las PAR-

49 Convención de Viena sobre el Derecho de los Tratados, artículo 31 párrafo 3, letra B).

50 Acuerdo de Marrakech por el que se establece la Organización Mundial del Comercio, artículo XVI párrafo 1.
TES CONTRATANTES del GATT de $1947 »^{51}$.

3) «Los Miembros afirman su adhesión a los principios de solución de diferencias aplicados hasta la fecha al amparo de los artículos XXII y XXIII del GATT de 1947 y al procedimiento desarrollado y modificado por el presente instrumento ${ }^{52}$.

4) «El sistema de solución de diferencias de la OMC es un elemento esencial para aportar seguridad y previsibilidad al sistema multilateral de comercio. Los Miembros reconocen que ese sistema sirve para preservar los derechos y obligaciones de los Miembros en el marco de los acuerdos abarcados y para aclarar las disposiciones vigentes de dichos acuerdos de conformidad con las normas usuales de interpretación del derecho internacional público. Las recomendaciones y resoluciones del OSD no pueden entrañar el aumento o la reducción de los derechos y obligaciones establecidos en los acuerdos abarcados.» ${ }^{53}$

De estas importantes disposiciones de la OMC el grupo especial en la diferencia «Japón - Bebidas Alcohólicas» ${ }^{54}$ observó en el párrafo 6.10 de su informe que «...los informes de los grupos especiales adoptados por las PARTES CONTRATANTES del GATT y por el Órgano de Solución de Diferencias de

\footnotetext{
51 GATT de 1994, $\mathrm{N}^{\circ}$ 1, letra b) iv).

52 ESD artículo 3 párrafo 1.

53 ESD artículo 3 párrafo 2.

54 Informe "Japón - Impuestos sobre las bebidas alcohólicas», distribuido en la OMC el 11 de julio de 1996.
} 
la OMC [...] constituyen una práctica ulteriormente seguida", la que "se encuentra en el apartado b) iv) del artículo 1 del GATT de 1994 por cuanto están incluidas en 'las demás decisiones de las PARTES CONTRATANTES del GATT de 1947’» y como "constituían la práctica ulteriormente seguida [...] habían de ser tenidos en cuenta por posteriores grupos especiales que examinaran la misma cuestión u otra análoga, pero [...] éstos no tenían que seguir forzosamente su razonamiento ni llegar a los mismos resultados».

En ese mismo párrafo 6.10 el grupo especial concluyó que los informes no aprobados "carecían de valor normativo en el sistema GATT o de la OMC» por lo que «no había de tenerlos en cuenta, al no constituir la práctica ulteriormente seguida", sin perjuicio de que un grupo especial "podía encontrar útiles orientaciones en el razonamiento seguido en un informe no adoptado [...] que a su juicio fuera pertinente».

Estados Unidos, parte reclamante en esa diferencia sobre las bebidas alcohólicas, apeló contra dicho informe $\mathrm{y}$, entre otras cuestiones, sostuvo que el grupo especial erró al calificar los informes adoptados como "práctica ulteriormente seguida», en el sentido dado por la Convención de Viena sobre el Derecho de los Tratados, pues los informes ya aprobados solo sirven para aclarar, en la diferencia particular de que se trate, la aplicación de los derechos y obligaciones de las partes, según las circunstancias concretas del caso. Además alegó que la 'decisión' al adoptar un informe, es una decisión en el sentido de lo dispuesto por el GATT de 1994 (párrafo 1.b.iv), pero que el informe del grupo especial ya aprobado, en cuanto tal, no constituye una 'decisión'.

El Órgano de Apelación ${ }^{55}$ manifestó que la esencia de una práctica ulteriormente seguida radica en una serie «concordante, común y coherente», de actos o declaraciones que bastan para dar a entender un acuerdo de las partes sobre la interpretación del tratado, por lo que un acto aislado no es suficiente para determinar esa práctica y declaró no considerar que las Partes Contratantes del GATT, al decidir adoptar un informe de un grupo especial, «tuvieran la intención de que su decisión constituyera una interpretación definitiva de las disposiciones pertinentes del GATT de $1947 »^{56}$. El Órgano agregó que los informes adoptados «son una parte importante del acervo del GATT» y los «grupos especiales posteriores suelen examinarlos» porque "crean expectativas legítimas en los Miembros de la OMC y, por consiguiente, deben tenerse en cuenta cuando son pertinentes para

55 Informe en apelación sobre "Japón - Bebidas Alcohólicas», distribuido el 4 de octubre de 1996.

56 La razón establecida por el Órgano de Apelación para desestimar la práctica ulterior está dada en que hoy la OMC consagra el mecanismo con quórum específico para obtener interpretaciones autorizadas o auténticas de parte de los Miembros de la OMC (cuestión que no se transcribió para concentrar el análisis del tema del precedente). 
Álvaro Espinoza • Algunas reflexiones sobre la solución en la organización mundial...

una diferencia», pero "no son obligatorios sino para solucionar la diferencia específica entre las partes en litigio", ${ }^{57}$ por lo que la «condición jurídica de estos informes no ha variado» tras la entrada en vigor de la OMC. En suma, el Órgano de Apelación no estuvo de acuerdo en que los informes de grupos especiales aprobados por las Partes Contratantes GATT y por el OSD de la OMC sean la práctica ulteriormente seguida en un caso concreto; tampoco estuvo de acuerdo en que los informes adoptados constituyan «por sí mismos» las demás decisiones de las Partes Contratantes del GATT de 1947.

Respecto de la situación de los informes no adoptados, el Órgano de Apelación compartió la conclusión del grupo especial (de aquel párrafo 6.10), en el sentido de que "carecían de valor normativo en el sistema del GATT o de la OMC» y estuvo de acuerdo en que un grupo especial pueda encontrar útiles orientaciones en el razonamiento seguido en un informe no aprobado.

Por su parte el informe del grupo especial en la diferencia «India - Patentes», ${ }^{58}$ expresamente indicó

57 En esta misma parte del informe transcrita figura una nota al pie ( $\left.\mathrm{N}^{\circ} 30\right)$ en la que el Órgano hace presente que el Estatuto de la CIJ «recoge explícitamente en su artículo 59 una disposición análoga», lo que «no ha impedido que esta Corte (y su predecesora) haya desarrollado una jurisprudencia en la que se distingue claramente el valor que se otorga a las decisiones anteriores». «India - Protección mediante patente de los productos farmacéuticos y químicos (tomando en consideración aquella jurisprudencia del Órgano de Apelación) "las decisiones anteriores de grupos especiales o del Órgano de Apelación no vinculan a los Grupos Especiales, aunque esas decisiones se refieran a la misma cuestión» aunque tendrá «en cuenta las conclusiones de los informes [...] y el razonamiento seguido en ellos». ${ }^{59}$

¿Y qué ocurre con los informes en apelación? A diferencia de los grupos especiales, el Órgano de Apelación se estableció con carácter "permanente» ${ }^{60}$ y su misión ${ }^{61}$ es pronunciarse sobre los posibles errores de derecho en la interpretación desarrollada por los grupos especiales en sus informes, ${ }^{62}$ por lo que el Órgano podrá confirmar, modificar o revocar las constataciones y conclusiones jurídicas del grupo especial. ${ }^{63} \mathrm{Como}$ el Órgano no está habilitado para conocer de los hechos en la diferencia, su tarea sería asimilable al de un tribunal de casación y esto lleva a Abi-Saab a concluir que «sería una suerte de suprema corte de jurisdicción para controlar la interpretación en la aplicación del derecho» (Abi-Saab, 2005; 10). ${ }^{64}$ En tal

para la agricultura», el que fue adoptado por el OSD el 22 de septiembre de 1998, sin que hubiera apelación

59 Párrafo 7.30 del Informe.

60 ESD artículo 17.1.

61 Siempre que una o más partes en la diferencia invoquen su intervención.

62 ESD artículo 17.6

63 ESD artículo 17 párrafo 13.

64 El Sr. Georges Abi-Saab se desempeñó como miembro del Órgano de Apelación de la OMC entre 2000 y 2008. 
sentido, es frecuente que en los informes de apelación aparezcan oraciones del estilo «como ya hemos tenido la oportunidad de referirnos a esta materia en la diferencia..."; ello demuestra que el Órgano busca la coherencia en sus propias opiniones al enfrentar materias que tienen vinculación con otras sobre las que ya se ha pronunciado.

Debido a que un determinado informe y su interpretación 'generan expectativas legítimas para los Miembros', ${ }^{65}$ Palmeter \& Mavroidis sostienen que al no seguirse un determinado precedente debiera explicarse tal situación, dando las razones de por qué no se aplicarán los criterios de ese informe previo (Palmeter \& Mavroidis, 2004; 57). Esta justificación racional apunta, naturalmente, a enfrentar las expectativas no satisfechas. Sin embargo, esto requiere un análisis de contexto para el caso en concreto, pues queda la impresión que todo dependiera exclusivamente del enfoque que los grupos especiales o el Órgano de Apelación le den al asunto que conocen. Pero aquí cabe considerar las altas expectativas de las mismas partes que, guiadas por sus propios y legítimos intereses, presentan su propia visión del caso y, para ello despliegan diversos argumentos, citando la jurisprudencia previa según su particular entendimiento.

Entonces, la tarea de un grupo especial y la del Órgano de Apelación se torna doble. Deberán elaborar las

65 Frase que aparece reiterada en la jurisprudencia sobre esta materia. razones jurídicas respecto de las normas citadas en la diferencia pudiendo apoyarse en la jurisprudencia previa, pronunciándose a la vez sobre las interpretaciones que las mismas partes en la diferencia han presentado respecto de las normas y cómo ellas entienden los precedentes alegados en su propio respaldo. Por ello, resulta de mucha importancia la participación de otros Miembros de la OMC, en su calidad de terceros en la diferencia, quienes, sin necesidad de tener interés comercial en la materia, están legitimados para intervenir ${ }^{66}$ y hacer presente cómo ellos entienden que las normas en juego han de interpretarse.

Está claro, entonces, que pese a que la jurisprudencia no es legalmente vinculante respecto de otros casos similares, el propio sistema de la OMC, a través de sus órganos de adjudicación, busca coherencia en sus decisiones con miras a aportar seguridad y previsibilidad, elementos esenciales para el desarrollo de las relaciones comerciales y que, además, constituyen uno de los fines que persigue el derecho: la certeza.

Pero este análisis no puede concluirse sin la cita de un reciente caso en la OMC de interés en la materia. En la diferencia «Estados Unidos - Medidas antidumping definitivas sobre el acero inoxidable procedente de México ${ }^{67} \mathrm{el}$ grupo especial se basó en constataciones de informes de otros grupos especiales

66 Por el artículo 10 del ESD.

67 Informe distribuido el 20 de diciembre de 2007. 
Álvaro Espinoza • Algunas reflexiones sobre la solución en la organización mundial...

que el Órgano de Apelación había revocado. Por ello México apeló, alegando que la actuación del grupo especial fue incompatible con el artículo 11 del ESD, pues el cometido de los grupos especiales es ayudar a cumplir las funciones del OSD y además que, según el artículo 3.2 del mismo ESD, el sistema de solución de diferencias es un «elemento esencial para aportar seguridad y previsibilidad». El Órgano sostuvo que está «firmemente establecido que los informes del Órgano de Apelación no son obligatorios sino para solucionar la diferencia específica entre las partes» pero "esto no significa que los grupos especiales posteriores tengan libertad para hacer caso omiso de las interpretaciones jurídicas y la ratio decidendi de los informes anteriores del Órgano de Apelación adoptados por el OSD ${ }^{68}$ y que «seguir las conclusiones a que ha llegado el Órgano de Apelación en diferencias anteriores no sólo es apropiado, sino que es precisamente lo que se espera de los grupos especiales, sobre todo cuando las cuestiones son las mismas». ${ }^{69}$ Así, el Órgano concluye que ve «con gran preocupación la decisión del Grupo Especial de apartarse de la jurisprudencia firmemente establecida del Órgano de Apelación que aclara la interpretación de las mismas cuestiones

68 Informe en apelación, párrafo 158.

69 Informe en apelación, párrafo 159 (precisamente esta parte es una cita de un pronunciamiento previo del Órgano en la diferencia «Estados Unidos - Exámenes por extinción respecto de artículos tubulares para campos petrolíferos», párrafo 188). jurídicas» porque aquel «criterio del Grupo Especial tiene graves consecuencias para el debido funcionamiento del sistema de solución de diferencias.» ${ }^{70}$ Por todo lo anterior y dado que el Órgano revocó todas las constataciones y conclusiones del grupo especial que fueron objeto de apelación, el Órgano «no formula otra constatación en el sentido de que el Grupo Especial incumplió los deberes que le imponía el artículo 11 del ESD $»^{71}$.

Una consideración especial merece esta conclusión del informe de apelación. El Órgano de Apelación revocó todos los aspectos del informe del grupo especial que fueron apelados, y dio las debidas razones de ello. Sin embargo, no se pronunció sobre si el grupo especial (que tomó en cuenta aspectos de otros informes revocados) había actuado o no contra las prescripciones del artículo 11 del ESD. Esta indicación tuvo un sentido más profundo que constatar que, gracias a la revocación de lo cuestionado, no era necesario un reproche sobre una posible contravención del artículo 11 del ESD. En efecto, tal como lo hizo presente la delegación de Chile en la reunión del OSD, durante la adopción de los informes en este caso: «el hecho de no seguir un precedente al pie de la letra no implica que un grupo especial esté actuando en contra de los deberes que establece dicho artículo 11, justa-

70 Informe en apelación, párrafo 162.

71 Conclusión d) del Órgano de Apelación, en el párrafo 165 (subrayado en el original). 
mente porque los precedentes no le son obligatorios». ${ }^{72}$

\section{CONCLUSiOneS}

Sobre los tres temas específicos aquí desarrollados el sistema del ESD en la OMC deja la sensación de un camino circular, pues se parte buscando caminos nuevos, pero se vuelve siempre a la orientación del gran camino principal. EL ESD tiene elementos singulares que lo distinguen y que, en cierto sentido, le apartan de la regla usual del derecho internacional, pero, a pesar de esas calificadas distinciones, se vuelve al núcleo central de las clásicas instituciones del derecho de gentes, a las que la misma OMC adhiere.

Respecto del primer tema, se trata de una controversia o diferencia, hay normas y prácticas que tratan el problema de las posiciones dispares como un asunto que aspira a ser siempre arreglado y en breve plazo, tal vez por la rapidez con que es preciso despejar las trabas al acceso a los mercados. Pero aún así, la 'diferencia' sigue participando de los elementos que la doctrina identifica como controversia internacional.

Sobre el segundo tema, los adjudicadores (grupos especiales y Órgano de Apelación) realizan una labor jurisdiccional al declarar el derecho aplicable y al pronunciarse sobre si

72 Declaración de Chile en la reunión del OSD del 20 de mayo de 2008. Párrafo 68 del Acta de la reunión. hay o no incumplimiento de parte de un Miembro. Esa jurisdicción viene a completarse con la acción colectiva de los Miembros de la OMC, en cuanto OSD, que sancionan los informes y someten a su supervisión la posterior implementación que corresponde al Miembro cuya medida se apartaba de la norma internacional. Por ello, es todo el sistema del ESD el que actúa en el mismo sentido que una función judicial; no obstante que ciertos autores le atribuyan el carácter de tribunal al Órgano de Apelación por las altas funciones que desempeña.

Por último, los precedentes no son jurídicamente vinculantes para un grupo especial en un caso nuevo. No obstante, ello no significa que, por no ser obligatorios, puedan ser desestimados sin razón alguna, ya que el sistema del ESD se nutre de un actuar que busca coherencia en las decisiones que se adoptan para reforzar la certeza que el derecho internacional procura como uno de sus principales fines.

\section{REFERENCIAS BIBLIOGRÁFICAS}

Abi-Saab, Georges (2005), «The WTO dispute settlement and general international law», en Yerxa, Rufus and Wilson, Bruce (ed.), Key issues in WTO dispute settlement the first ten years, Cambridge, Cambridge University Press.

Brownlie, Ian (2003), Principles of public international law, Oxford University Press, $6^{\text {th }}$ edition.

Couture, Eduardo J. (1983), Vocabulario jurídico, Buenos Aires, Ediciones Depalma (segunda reimpresión). 
Álvaro Espinoza • Algunas reflexiones sobre la solución en la organización mundial...

Jackson, John H. (2000), The Jurisprudence of GATT \& the WTO, Cambridge, Cambridge University Press (reprinted 2002).

Jackson, John H. (2006), Sovereignty, the WTO, and changing fundamentals of International Law, Cambridge, Cambridge University Press.

Organización Mundial del Comercio (1996): Informe del grupo especial en la diferencia «Japón - Impuestos sobre las bebidas alcohólicas», documento WT/DS8/R WT/ DS10/R WT/DS11/R, distribuido el 11 de julio de 1996 y adoptado el 1 de noviembre de 1996. Disponible en el portal www.wto.org

Organización Mundial del Comercio (1996): Informe del Órgano de Apelación en la diferencia "Japón - Impuestos sobre las bebidas alcohólicas», documento WT/ DS8/AB/R WT/DS10/AB/R WT/DS11/ $\mathrm{AB} / \mathrm{R}$, distribuido el 4 de octubre de 1996 y adoptado el 1 de noviembre de 1996 . Disponible en el portal www.wto.org

Organización Mundial del Comercio (1998): Informe del grupo especial en la diferencia «India - Protección mediante patente de los productos farmacéuticos y químicos para la agricultura», documento WT/ DS79/R distribuido el 24 de agosto de 1998 y adoptado el 22 de septiembre de 1998. Disponible en el portal www. wto.org

Organización Mundial del Comercio (2001): Informe del Órgano de Apelación en la diferencia sobre implementación en el caso 'México - Investigación antidumping sobre el jarabe de maíz con alta concentración de fructosa procedente de Estados Unidos', documento WT/DS132/AB/RW distribuido el 22 de octubre de 2001 y adoptado por el OSD el 21 de noviembre de 2001. Disponible en el portal www. wto.org

Organización Mundial del Comercio (2005): Procedimientos de trabajo para el examen en apelación, documento WT/AB/WP/5, de 4 de enero de 2005, disponible en el portal www.wto.org
Organización Mundial del Comercio (2008): Informe del Órgano de Apelación en la diferencia «Estados Unidos - Medidas antidumping definitivas sobre el acero inoxidable procedente de México", documento WT/DS344/AB/R distribuido el 30 de abril de 2008 y adoptado el 20 de mayo de 2008. Disponible en el portal www.wto.org

Organización Mundial del Comercio (2008): Acta de la reunión del Órgano de Solución de Diferencias de fecha 20 de mayo de 2008, documento WT/DSB/M/250. Disponible en el portal www.wto.org

Palmeter, David \& Mavroidis, Petros (2004), Dispute Settlement in the World Trade Organization, Cambridge, Cambridge University Press.

Pastor Ridruejo, José Antonio (2003), Curso de derecho internacional público y organizaciones internacionales, Madrid, Editorial Tecnos.

Pauwelyn, Joost (2003), Conflict of norms in Public International Law, Cambridge, Cambridge University Press (reprinted 2005).

Van den Bossche, Peter (2005), «The making of the 'World Trade Court': the origins and development of the Appellate Body of the World Trade Organization", en Yerxa, Rufus and Wilson, Bruce (ed.), Key issues in WTO dispute settlement - the first ten years, Cambridge, Cambridge University Press. 